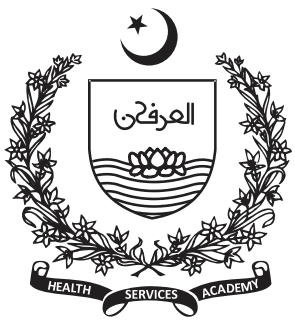

\title{
Assessing Nurses' Knowledge regarding Ventilator Mechanics
}

\author{
Nasreen Rafiq, Farida Bibi Mughal, Komal Valliani
}

Aga Khan University

School of Nursing and

Midwifery

Corresponding Author:

Nasreen Rafiq

Email:

nasreenrafiq93@gmail.com

\section{Abstract}

Background: Advanced ventilation technologies require critical nursing management to facilitate patientcare. The nursing workforce in the intensive care units (ICUs) should have basic knowledge and understanding of the ventilator and its mechanics to recognise adverse events and improve the care quality.

Methods: A pre-experimental study using an educational intervention was conducted in the ICUs at a tertiary care hospital, was conducted to assess the baseline knowledge of nursing staff about ventilator mechanics and respiratory physiology, and to identify the effectiveness of the module and teaching sessions on their knowledge score. A self-administered and structured questionnaire was used to collect data. A self-developed educational module was used as an intervention. Descriptive analysis was reported for demographic characteristics; paired t-test was conducted to identify difference in mean scores before and after intervention; and stratified analysis was also performed.

Results: The knowledge scores significantly increased at $95 \% \mathrm{Cl}(\mathrm{P}$-value $=$ $0.00)$ after conducting the intervention. The mean post-test score was significantly higher with a difference of 7.77 (P-value < 0.05$)$.

Conclusion: Nursing knowledge regarding ventilator mechanics becomes important to ensure safe and quality nursing care. Continuous professional nursing education is important to improve nursing knowledge and quality patientcare.

Keywords: Ventilator mechanics, nurses' knowledge and intensive care unit

\section{Introduction}

$\mathrm{T}$ he patients in the intensive care units are acutely sick, usually dependent on life supporting mechanical devices (1). The life of these mechanically ventilated patients is reliant on healthcare professionals, particularly nurses, for care (2). The knowledge and competence of the nursing staff can determine the health or demise of patients in the intensive care units (3). The modern intensive care units are equipped with advanced technology requiring prompt nursing management (4). The advanced technology in the critical care units cannot benefit unless integrated with the patients' condition $(3,4)$; neither can these technologies help patients unless nurses demonstrate critical knowledge and understanding regarding these mechanical devices (3). However, it is frequently found in the critical care literature that nurses working in the intensive care units usually lack basic knowledge and competence about the ventilator mechanics in relation to the respiratory physiology, which questions the quality of care and safety of intubated patients (4).

The positive pressure invasive ventilation is a mechanical intervention, and its need is the most common reason behind the admissions in the intensive 
care units (5). The respiratory emergencies require critical thinking, prompt decision-making, and instant life-saving measures that comes from basic understanding of ventilator mechanics in relation to the respiratory physiology (6). The invasive mechanical ventilation proffers various challenges to nurses due to the unique nature of several lung pathologies requiring different types of artificial ventilation (7).

Nurses play a vital role in contributing to patients' health and recovery in the high dependency areas since many ventilator - related decisions are made based on nurses' collaboration with doctors (7). Inappropriate ventilator settings in association with the respiratory pathologies and inability of nurses to identify potential deterioration can result in severe consequences, various complications, and prolong hospital stay (4). A data from a clinical survey ( $n=38$ nurses) revealed that $62 \%$ of the mechanically ventilated patients suffered through breathlessness due to nurses' failure of recognizing the ventilator parameters (3). Similarly, a quantitative descriptive study revealed that intensive care nursing staff showed poor knowledge and competence related to the ventilator mechanics and mechanical ventilation (4). Moreover, the results of an audit of Critical Care Society of Southern Africa highlighted that $75 \%$ of the intensive care nurses lacked basic understanding and competence related to the fundamental ventilator mechanics; but were still independently dealing with the intubated patients (4). Likewise, a study conducted in Sudan, utilizing the pretest and post-test method, illustrated that nurse had poor scores for knowledge about ventilator mechanics and associated complications in the pre-test, but the scores significantly improved in the post-test $(\mathrm{P}<0.05)$ after the introduction of an educational training session (8). According to a study, the mean mortality rate in the intensive care units is $50 \%$ in Pakistan (9). Similarly, a descriptive cross-sectional study conducted in Sialkot, also identified a mortality rate of $51.7 \%$ among intubated patients in Pakistan with 32\% related to the ventilator associated events (9), which include incompetence in ventilator handling and adequate knowledge about its functioning resulting in various nosocomial infections such ventilator associated pneumonia and patients' distress (10). Being the central care providers, nurses can play a pivotal role in decreasing the incidences of such events. Successful mechanical ventilation needs a fundamental and comprehensive understanding of human respiratory functioning and ventilator dynamics along with the intensive nursing care (11).

Inappropriate ventilator settings and nurses' failure to identify associated deterioration in pulmonary functions can result in various pulmonary pathologies and injuries contributing to initial lung complications (4). Lack of ventilator knowledge and its ineffective handling also result in various ventilator associated infections (9). Ventilator associated pneumonia (VAP) is the most prevalent infection in the intensive care units of Pakistan with a prevalence rate of at-least $70 \%$ (9). A cross-sectional study ( $\mathrm{n}=100$ nurses) conducted in the intensive care units of both the public and private hospitals of Pakistan showed lack of nurses' knowledge about mechanical ventilation resulting in increased incidences of VAP (12). A prospective audit of 126 mechanically ventilated patients conducted in the intensive care unit of a tertiary care hospital in Pakistan revealed aspiration of secretions into lungs and blockage of endotracheal tube as the most frequent complications of mechanical ventilation that indicate lack of staff knowledge and competencies while dealing with ventilators (13). Nurses dealing with intubated patients should have basic understanding of the ventilator mechanics in association to the respiratory physiology to identify potentially adverse events, prevent complications, and facilitate weaning (4). However, limited studies were found internationally that assessed nurses' knowledge about the ventilator mechanics and respiratory physiology, and no such study was found in the Pakistani context. It provided the researchers an opportunity to assess the baseline knowledge of nursing staff about basic ventilator mechanics and respiratory physiology, educate them to improve patient care, and re-asses their knowledge. Hence, the study aimed to assess the baseline knowledge of nursing staff about ventilator mechanics and respiratory physiology and identify the effectiveness of the module and teaching sessions on their level of knowledge.

\section{Methodology}

A pre-experimental study using an educational intervention was conducted in the medical and surgical Intensive Care Units (ICUs) of a Joint Commission International (JCI) Accredited private tertiary care hospital in Karachi, Pakistan. The study was approved by the Ethical Review Committee (2020-5590-14855) of the tertiary care hospital. Non-probability convenient 
sampling technique was used to recruit the study participants.

A total of 30 nursing staff from both the medical and surgical ICUs were recruited for the study. The course was primarily directed to nursing staff including registered nurses, nurse technicians, and nurse interns. The invitation to the course was diffused through an announcement during their routine session.

All male and female nursing staff, with a minimum nursing experience of six months in the intensive care unit, directly involved in taking care of patients on a ventilator and agreed to consent were included in the study. Staff on leaves during the study period were excluded from the study.

The study was initiated with a written consent. Each participant was given a unique identification number to ensure the anonymity of the findings. To collect the data, a self-administered structured knowledge questionnaire was developed consisting of two parts. The first part comprised of demographic details and the other part included 20 multiple choice questions to assess the baseline knowledge of nursing staff regarding the ventilator mechanics in association with respiratory physiology. Each question had only one correct answer.

The questionnaire was developed based on a literature review which was reviewed by a team of experts including two intensivists, an intensive care nurse specialist, and a respiratory therapist to ensure the face validity. Finally, the questionnaire was administered to the participants as the pre-test, and their scores were calculated. Based on the pre-test results, an educational module was developed following the principles of teaching and learning (14); and reviewed by the experts. The module was a conscience educational document, which had information regarding the (a) basic respiratory physiology (b) invasive mechanical ventilation, (c) criteria for its initiation, (d) basic ventilator variable and settings, (e) modes of ventilation, (f) troubleshooting in association with alarm settings, and (g) complications of invasive mechanical ventilation. Six teaching sessions were conducted to ensure the delivery of quality content to the participants, followed by a post-test to re-assess their knowledge.

\section{Results}

The data was analyzed using SPSS version 17. A descriptive analysis was conducted to report demographic characteristics in frequency and percentage. Mean and the standard deviation were calculated for the pre-test and post-test knowledge scores. A paired t-test was applied to identify the mean difference in the scores before and after administering the module along with the teaching sessions. Stratified analysis of pre-test and post-test mean scores were conducted through experience, designation, and highest education credential.

A total of 30 nursing staff participated from both the medical and surgical ICUs. Table 1 shows the demographic characteristic of participants. Among the staff, 18 were registered nurses, 03 were nurse technicians, and 09 were nurse interns. The majority of the participants $(30 \%)$ had intensive care experience between 6 months to 1 year and 5 to 7 years. However, only $2(6.67 \%)$ participants had enriched intensive care experience of $>10$ years. Half of the group had the highest educational credential as Bachelor's of Science in Nursing (Table 1).

Table 1. Demographic characteristics of the participants

\begin{tabular}{|c|c|c|c|}
\hline \multicolumn{2}{|c|}{ Demographic Variables } & Frequency & Percentage (\%) \\
\hline \multirow{5}{*}{ Experience } & 6 months -1 year & 9 & $30 \%$ \\
\hline & 2- 4 years & 5 & $16.67 \%$ \\
\hline & $5-7$ years & 9 & $30 \%$ \\
\hline & $8-10$ years & 5 & $16.67 \%$ \\
\hline & $>10$ years & 2 & $6.67 \%$ \\
\hline \multirow{3}{*}{ Designation } & Registered nurse & 18 & $60 \%$ \\
\hline & Nurse Technician & 3 & $10 \%$ \\
\hline & Nurse Intern & 9 & $30 \%$ \\
\hline \multirow{5}{*}{$\begin{array}{l}\text { Highest } \\
\text { education } \\
\text { credential }\end{array}$} & Matriculation & 0 & 0 \\
\hline & Intermediate & 3 & $10 \%$ \\
\hline & Diploma in Nursing (RN) & 12 & $40 \%$ \\
\hline & $\begin{array}{l}\text { Bachelors of Science in } \\
\text { Nursing (BScN) }\end{array}$ & 15 & $50 \%$ \\
\hline & $\begin{array}{l}\text { Masters of Science in Nursing } \\
(\mathrm{MScN})\end{array}$ & 0 & 0 \\
\hline
\end{tabular}

The results of the paired t-test revealed a significant difference in the pre-test and post-test knowledge scores of the participants. Table 2 revealed significant differences in mean scores of knowledge in pre-test and post-test using a paired t-test. There was a significant $(p=0.00)$ improvement in post-test scores for nurses' knowledge of ventilator mechanics and respiratory physiology. The pre-test knowledge score showed a mean score of $9.43 \pm 3.43$ which comparatively improved after delivering the educational module along with the teaching sessions in the post-test 17.2 \pm 2.19 . 
Table 2. Difference between the knowledge of nurses before and after the teaching session

\begin{tabular}{|c|c|c|c|c|}
\hline & Mean & N & Standard Deviation & SE Mean \\
\hline Pre-test scores & 9.4333 & 30 & 3.43093 & 0.62640 \\
\hline Post-test scores & 17.2000 & 30 & 2.18774 & 0.39942 \\
\hline \multicolumn{4}{|c|}{ 95\% Cl for mean difference: (-8.84838; -6.68495$)$} \\
\hline \multicolumn{4}{|c|}{ t - test of mean difference $=7.77:$ P-Value $=0.000$} \\
\hline
\end{tabular}

A stratified analysis of knowledge scores before and after the teaching session was highly significant ( $p$ value <0.05) for all the variables except for the experience greater than the 10 years (Table 3 ).

Table 3. Stratified Analysis of knowledge scores of nurses before and after the teaching session

\begin{tabular}{|c|c|c|c|c|}
\hline $\begin{array}{l}\text { Demograp } \\
\text { hic } \\
\text { Variables }\end{array}$ & $\begin{array}{l}\text { Mean } \\
\text { Score } \\
\text { Before } \\
\pm \text { SD }\end{array}$ & $\begin{array}{l}\text { Mean } \\
\text { Score } \\
\text { After } \\
\pm S D\end{array}$ & $\begin{array}{l}\text { Mean } \\
\text { Differen } \\
\text { ce }\end{array}$ & $\begin{array}{l}\text { P- } \\
\text { valu } \\
\text { e }\end{array}$ \\
\hline \multicolumn{5}{|l|}{ Experience } \\
\hline $\begin{array}{l}6 \text { months- } 1 \\
\text { year }\end{array}$ & $\begin{array}{l}5.77 \pm 2.7 \\
7\end{array}$ & $\begin{array}{l}15.67 \pm 2 . \\
84\end{array}$ & -9.88 & 0.000 \\
\hline 2-4 years & $9.2 \pm 1.09$ & $17 \pm 1.87$ & -7.8 & $\begin{array}{l}0.000 \\
2 \\
\end{array}$ \\
\hline 5-7 years & $\begin{array}{l}10.77 \pm 1 . \\
86\end{array}$ & $\begin{array}{l}18.11 \pm 1 . \\
69\end{array}$ & -7.3 & 0.000 \\
\hline $8-10$ years & $12 \pm 2.92$ & $\begin{array}{l}18.6 \pm 1.9 \\
5\end{array}$ & -6.6 & $\begin{array}{l}0.004 \\
8\end{array}$ \\
\hline$>10$ years & $14 \pm 1.41$ & $17 \pm 2.83$ & -3 & 0.204 \\
\hline \multicolumn{5}{|l|}{ Designation } \\
\hline $\begin{array}{l}\text { Registered } \\
\text { Nurse }\end{array}$ & $\begin{array}{l}10.78 \pm 2 . \\
02\end{array}$ & $\begin{array}{l}17.78 \pm 1 \\
73\end{array}$ & -7 & 0.000 \\
\hline $\begin{array}{l}\text { Nurse } \\
\text { Technician }\end{array}$ & $\begin{array}{l}12.33 \pm 4 \\
04\end{array}$ & $\begin{array}{l}18.33 \pm 2 . \\
89\end{array}$ & -6 & 0.000 \\
\hline $\begin{array}{l}\text { Nurse } \\
\text { Intern }\end{array}$ & $\begin{array}{l}5.77 \pm 2.7 \\
7\end{array}$ & $\begin{array}{l}15.67 \pm 2 . \\
24\end{array}$ & -9.89 & 0.000 \\
\hline \multicolumn{5}{|c|}{ Highest Education Credential } \\
\hline $\begin{array}{l}\text { Intermedia } \\
\text { te }\end{array}$ & $\begin{array}{l}12.33 \pm 4 \\
04\end{array}$ & $\begin{array}{l}18.33 \pm 2 . \\
87\end{array}$ & -6 & $\begin{array}{l}0.026 \\
7 \\
\end{array}$ \\
\hline $\begin{array}{l}\text { Diploma in } \\
\text { Nursing } \\
\text { (RN) }\end{array}$ & $\begin{array}{l}9.33 \pm 3.3 \\
4\end{array}$ & $\begin{array}{l}16.83 \pm 2 \\
48\end{array}$ & -7.5 & 0.000 \\
\hline $\begin{array}{l}\text { Bachelors } \\
\text { of Science } \\
\text { in Nursing } \\
(\mathrm{BScN})\end{array}$ & $\begin{array}{l}8.93 \pm 3.3 \\
5\end{array}$ & $\begin{array}{l}17.27 \pm 1 \\
87\end{array}$ & -8.33 & 0.000 \\
\hline
\end{tabular}

\section{Discussion}

The use of educational module along with the teaching sessions have always been the effective learning strategies to improve knowledge. Globally, several studies have been conducted, which reported that nurses lack adequate knowledge regarding ventilator mechanics (4, 15-16); and educational modules and various teaching sessions can facilitate in increasing their knowledge and competency (16-19). The significant difference in pre-test and post-test of the current study revealed that education can be a key to bring a change in the knowledge level. The research findings in one of the pre-test and post-test studies conducted on 50 nurses in a teaching hospital at Nassiryah City were congruent with the current study findings and reported that nurses had weak knowledge regarding the complication prevention in association with the ventilator mechanics; however, the knowledge scores improved after the application of an educational program (16). Similarly, in a systematic review, 17 of 12 articles including quasi experimental and pre-and postintervention observational design revealed that educational programs for nurses about mechanical ventilation showed statistically significant improvement in patient outcomes including successful weaning trials, increased ventilation compliance, decreased length of intubation and hospital stay, and reduced incidences of VAP (17).

Certain demographic variables including highest educational qualification, years of experience in intensive care unit, and designation may also have an effect on participants' knowledge. In the current study, $40 \%$ participants were diploma holders. According to Pakistan Nursing Council curriculum for Diploma, the students are expected to spend 230 hours including both theoretical components as well clinical rotation to the critical care areas (18). Despite exposure to critical care setting during studies, the on-ground diploma nurses need time as well as sufficient knowledge to become competent in the critical care area. There can be plausibility that a gap exists between learned theoretical concepts and its application in the clinical setting, because of which, there can be low level of knowledge among critical care nurses regarding ventilator mechanics in association with the respiratory physiology. Furthermore, in Pakistan there is a lack of specialized training programs in critical care areas which can help nurses to be equipped with the required knowledge and grow in the same field. However, they are expected to perform according to the set standards 
of critical care setting for which they are not adequately trained. Therefore, it can be inferred that nurse need frequent trainings along with the supervision so that they can learn and re-learn the concepts regarding ventilator mechanics in relation with the respiratory physiology, which will help them to gradually develop competency. The lack of knowledge about ventilator dynamics among nursing staff can also be related to the number of years of experience. In this study 09 participants $(30 \%)$ were nursing interns with 6 months to 1 year of work experience in the intensive care unit. This is also supported by a quantitative cross-sectional survey ( $\mathrm{n}=101$ critical care nurses) conducted in Finland, which showed that the mean knowledge score of experienced nurses were significantly better than less experienced nurses (19).

\section{Strength and Limitations}

As per the researcher's knowledge, this is the first study of its kind in Pakistan, that assessed the baseline knowledge of nursing staff about basic ventilator mechanics and respiratory physiology, educated them to improve patient care, and re-assessed their knowledge. The study also highlighted the importance of continuous professional education for nursing development and quality patient care in the high dependency units. However, the study was conducted in the medical and surgical intensive care unit of a single tertiary care hospital, with a sample of 30 participants only. Hence, its findings cannot be generalized to the other settings. Also, the study assessed the short-term effects of the education module on participants' knowledge. The long-term effects on knowledge were not identified.

\section{Recommendations}

In view of the study findings, following are the recommendations for nursing education, nursing practice, and nursing management.

\section{Nursing Education}

- All nursing staff should be educated for the basic ventilator mechanics in order to ensure patient safety and quality care.

- Nursing education services should assess knowledge of nursing staff sent to intensive care units to ensure safe care.

- The presentation on ventilator mechanics in the advance critical care course offered by nursing education services should be revised, updated, and improved.

- Ongoing educational trainings specific to mechanical ventilation in the clinical environment of the intensive care unit should be ensured.

\section{Nursing Practice}

- Nurses involved in direct care of the mechanically ventilated patient should have ongoing clinical assessments with regard to their knowledge and competency to care deal with mechanical ventilation.

- Nursing staff should be appreciated to participate in making ventilator related discussions for their patients. ICU orientation module should be revisited, and the power point presentation and the module developed under this project, should be added as a source material for nursing staff in their competencybased orientation (CBO) period.

- Individually, all nursing staff should take interest in learning and managing technologies in addition to the routine nursing tasks; they should realize it as one of the responsibilities of critical care nurses to be aware about fundamental ventilator management to improve their knowledge and practices.

\section{Nursing Management}

- Nursing management and team leaders should ensure their own competencies related to the mechanical ventilation to remain updated with modern technologies and ventilation trouble shooting in order to guide the nursing staff.

- They should also ensure adequate supervision of the nursing staff dealing with intubated patient, and be certain of staff knowledge and competence level while assigning patients.

- At institutional level, root cause analysis should be done to identify nurses' learning needs to increase the capacity building opportunities and facilitate better patient care.

\section{Conclusion}

This study indicated that nursing knowledge regarding ventilator mechanics improved after the implementation of teaching module. Nursing staff reported substantial improvement in their knowledge scores which will help in promoting safe and quality patient care in the intensive care units in future. Further research including large sample size and involving various study settings will add to the scientific evidence of continuous training session to improve critical care nurses' knowledge. 


\section{References}

1. Ayub F, Haider IZ, Saeed S, Murtaza B, Tariq M. Shortterm outcomes in patients undergoing mechanical ventilation in a tertiary care centre in Sialkot. PAFMJ. 2018;68(4):1007-12.

2. Botha L. level of nurses' competence in mechanical ventilation in intensive care units of two tertiary health care institutions in Gauteng. 2012

3. Haugdahl HS. Mechanical ventilation and weaning: Roles and competencies of intensive care nurses and patients' experiences of breathing. 2016

4. Jansson M, Ala-Kokko T, Ylipalosaari P, et al. Critical care nurses' knowledge of, adherence to and barriers towards evidence-based guidelines for the prevention of ventilator-associated pneumonia-A survey study. Intensive and Critical Care Nursing. 2013;29(4):216- 227.

5. Khan F H, Khan FA, Irshad R, et al. Complications of endotracheal intubation in mechanically ventilated patients in a general intensive care unit. J Pak Med Assoc. 2010;46:195.

6. Locsin RC, Kongsuwan W. Lived experience of patients being cared for in ICUs in Southern Thailand. Nursing in Critical Care. 2013;18 (4), 200-211.

7. Mellott KG, Grap MJ, Munro CL, et al. Patient ventilator asynchrony in critically ill adults: Frequency and types. Heart \& Lung: The Journal of Acute and Critical Care, 2014;43(3):231-243.

8. Hammod HJ, Mohammed S. Effectiveness of an Educational Program on Nurses Knowledge Concerning Complications Prevention of Mechanical Ventilation at Intensive Care Unit in Al-Hussain Teaching Hospital at Nassiryah City. Kufa journal for nursing sciences. 2016 Aug 29;6(2).

9. Ratnani I, Khan S, Ashraf S, et al. ICU mortalities in a Pakistan tertiary care center: Call for preventive and logistic interventions. Crit Care Med. 2019;47(1):147

10. HB US, Atif I, Rashid F, Zulfiqar H, Mian K, Sarfraz M, Batool M, Khan UG. Knowledge and practices of critical care health professionals related to ventilator associated pneumonia in tertiary care hospitals of Islamabad and Rawalpindi. JPMA. The Journal of the Pakistan Medical Association. 2017 Nov 1;67(11):1714-8.
11. Windisch W, Dreher M, Geiseler J, et al. Guidelines for non-invasive and invasive home mechanical ventilation for treatment of chronic respiratory failure-Update 2017. Pneumologie (Stuttgart, Germany). 2017;71(11):722-795.

12. Zeb A, Muhammad H, Ahmad I, et al. Nurses' Knowledge Regarding Prevention of Ventilator Associated Pneumonia. LOJ Nursing in Health Care. LOJNHC. 2018;2 (1).

13. Zilberberg MD, de Wit M, Shorr AF. Accuracy of previous estimates for adult prolonged acute mechanical ventilation volume in 2020: update using 2000-2008 data. Cril Care Med. 2012;40(1):18-20.

14. Bastable, SB. Nurse as educator: Principles of teaching and learning for nursing practice. Jones \& Bartlett Learning. 2017.

15. Chlan L, Tracy MF, Grossbach I. Achieving quality patient-ventilator management: advancing evidencebased nursing care. Critical Care Nurse. 2011 Dec;31(6):46-50.

16. Mohammed SJ, Hammod HJ. Effectiveness of an Educational Program on Nurses Knowledge Concerning Complications Prevention of Mechanical Ventilation at Intensive Care Unit in Al-Hussain Teaching Hospital at Nassiryah City. Kufa Journal for Nursing sciences. 2016;6(2):201-10.

17. Guilhermino MC, Inder KJ, Sundin D. Education on invasive mechanical ventilation involving intensive care nurses: a systematic review. Nursing in critical care. 2018 Sep;23(5):245-55.

18. Curriculum of Nursing Educational Programs [Internet]. Pnc.org.pk. 2021 [cited 21 June 2021]. Available from: https://www.pnc.org.pk/Curriculum_of_Nursing_Edu cational_Programs.htm

19. Jansson M, Ala-Kokko $T$, Ylipalosaari $P$, Syrjälä $H$, Kyngäs H. Critical care nurses' knowledge of, adherence to and barriers towards evidence-based guidelines for the prevention of ventilator-associated pneumonia-A survey study. Intensive and Critical Care Nursing. 2013 Aug 1;29(4):216-27. 